\title{
Effect of valproic acid administration during pregnancy on postnatal development of cerebellar cortex and the possible protective role of folic acid
}

\author{
S.I. Shona, A.A. Rizk, A.O. El Sadik, H.Y. Emam, E.N. Ali \\ Anatomy and Embryology, Faculty of Medicine, Cairo University, Egypt \\ [Received: 18 July 2017; Accepted: 20 September 2017]
}

Background: Valproic acid (VPA), one of the most important antiepileptic drugs, proved to be inevitable for epileptic pregnant women to limit the hazards of convulsions on the foetuses and mothers. Periconceptional folic acid supplementation was investigated to protect against several birth defects. However, its role against VPA cerebellar toxicity was not properly investigated. The present study was conducted to evaluate the protective effect of folic acid against VPA cerebellar neurotoxicity.

Materials and methods: Twenty-four pregnant female albino rats were divided into three groups; group I (control group, did not receive any drugs), group II (given VPA at a dose of $50 \mathrm{mg} / \mathrm{kg}$ body weight once daily) and group III (given the same dose of VPA and $400 \mathrm{\mu g} / \mathrm{kg}$ of body weight folic acid once daily). Ten male offspring from each group were sacrificed at two ages: at 2 and 12 weeks after birth. Samples of cerebellar cortex were taken and prepared for light, electron microscopic examination, glial fibrillary acidic protein (GFAP) immunohistochemical study and histomorphometric analysis.

Results: The present study confirmed the neurotoxic effect of prenatal VPA on the cerebellar cortex, especially on Purkinje cells. The cells appeared shrunken, reduced in density, disorganised and surrounded by empty haloes. Nuclear damage and axon degeneration in the form of vacuolation, loss of organelles and absence of neurofilaments with myelin sheath depletion were detected. Concomitant supply of folic acid was shown to retain the normal architecture of Purkinje cells with their axons and nuclei. In many animals receiving folic acid, the thickness of all layers of the cortex increased up to that of the control groups, after being markedly reduced in VPA-treated groups. GFAP immunoreaction was also improved against the strong positive gliosis detected in VPA-treated groups.

Conclusions: The present study confirmed the protective role of folic acid against the cerebellar neurotoxic effects of VPA prenatal exposure. It is recommended that folic acid supplements should be given to every epileptic pregnant mother treated with VPA. (Folia Morphol 2018; 77, 2: 201-209)

Key words: cerebellum, valproic acid, folic acid, glial fibrillary acidic protein, ultrastructure 


\section{INTRODUCTION}

Valproic acid (VPA) is a branched-chain carboxylic acid. It is the most widely used antiepileptic drug due to its great influence on a broad range of seizure types [6]. VPA proved to be unavoidable and could not be excluded in epileptic pregnant women [24]. Noncontrolled epileptic attacks during pregnancy produce high risk of injury to both mother and foetus [15]. However, VPA has been shown to cross the placenta and accumulate in the foetal circulation with higher concentration than that in the maternal blood, causing toxicity and teratogenicity [25].

Several studies detected that prenatal VPA exposure induced marked degeneration of the cerebellar Purkinje and granular cells [17, 21-23]. A reduction of the size of the cerebellar hemisphere and Purkinje cell number were found after VPA injection on day 12 of gestation in rats [10]. However, few studies investigated the effects of VPA on gliogenesis in the developing brain. They found alteration in the postnatal density of microglia and astrocytes after prenatal VPA administration [14, 16].

It was demonstrated that VPA initiated proteins and genes toxicity that have important roles in directing differentiation and growth during organogenesis with the production of multiple apoptotic cascades [9]. Foetal malformation and cellular damage induced by VPA were reported to be caused by increasing the total body free radicals [19]. Vitamin B9 (folate) was found to be an essential co-factor in the regulation of gene expression and new protein production which is vital for foetal cell differentiation, development and growth [13]. However, the study of the protective role of folic acid in prenatal VPA cerebellar toxicity was not properly investigated. Therefore, the aim of the present study was to examine the possible protective effects of folic acid on the histological and ultrastructural postnatal changes in the development of cerebellar cortex after prenatal VPA administration.

\section{MATERIALS AND METHODS}

\section{Chemicals}

Valproic acid. Supplied as a syrup form of VPA (as sodium salt) $250 \mathrm{mg} / 5 \mathrm{~mL}$; oral solution, a product of Sanofi Company, Egypt.

Folic acid. Supplied as tablets $(5 \mathrm{mg}$ ) a product of El-Nile Company for pharmaceutical and chemicals, Egypt. Each tablet was dispersed in $10 \mathrm{~mL}$ of distilled water. Each $\mathrm{mL}$ of the produced suspension contains $500 \mu \mathrm{g}$ of folic acid. Prior to administration of the required dose, the drug suspension was vortexed to ensure homogenous dispersion of the drug.

\section{Animals}

A total of 24 adult female Sprague Dawley albino rats weighting 200-250 g each and 4-5 months old were used in the current study. Other 6 adult male albino rats were used for breeding. The rats were locally bred at the animal house at Faculty of Medicine, Cairo University, Egypt. They were housed at room temperature, had access to food and water ad libitum. The animals were given 2 weeks acclimatisation period before starting the experiment. They were treated in accordance with the international guidelines for the care and use of laboratory animals and the experiment protocol was approved by the Ethics Committee, Faculty of Medicine, Cairo University, Egypt.

\section{Experimental design}

Female and male rats were housed separately (4 females and 1 male). Fertilisation was confirmed by vaginal smear examination every morning. The presence of vaginal plug was designed as day zero of gestation. Female rats with successful breeding were caged separately. The pregnant rats were equally divided into three groups (8 rats in each group) as follows:

- Group I (control group) - the rats of this group received no medications.

- Group II (VPA-treated group) - received VPA at a dose of $50 \mathrm{mg} / \mathrm{kg}$ body weight once daily by gastric gavage from day one of pregnancy; which is the therapeutic dose of VPA used in the treatment of epilepsy and seizures [18].

- Group III (VPA- and folic acid-treated group) received VPA at a dose of $50 \mathrm{mg} / \mathrm{kg}$ body weight concomitantly with folic acid at a dose of $400 \mu \mathrm{g} /$ /kg body weight by gastric gavage once daily from day one of pregnancy; which is the protective dose given during pregnancy [28].

Ten male offspring from each group were sacrificed at two ages: at 2 and 12 weeks after birth (twenty rats from each group), forming the following subgroups for each group:

- Subgroup A - 2-week-old offspring.

- Subgroup B - 12-week-old offspring.

The skull of each rat was opened by a circular incision from all-around. The skull cap was removed and the cerebrum was elevated and retracted by blunting methods. The dural folds were cut, then the 
cerebellum was removed cautiously and prepared for the following studies.

\section{Light microscopic study}

Two cubic mm, cut from different areas of the cerebellar surface which represent the cerebellar cortex of the offspring, were immediately removed and fixed in Bouin solution, dehydrated in ascending series of ethanol, cleared in methyl benzoate and embedded in paraffin wax. Paraffin sections of 5-6 microns were prepared and stained with haematoxylin and eosin (H\&E) stain [8] for routine histological examination.

\section{Immunostaining of GFAP}

Paraffin sections were deparaffinised on charged slides for localisation of glial fibrillary acidic protein (GFAP) using avidin-biotin complex $(A B C)$. Nonspecific endogenous peroxidase activity was blocked by treatment with $0.9 \%$ hydrogen peroxide in absolute methanol for $10 \mathrm{~min}$ then incubated with the primary anti-GFAP antibody at 1:100 dilutions for $20 \mathrm{~min}$ at room temperature. Mouse monoclonal antibody (Glial Fibrillary Acidic Protein) Ab-1 (Clone GA-5) was used, which is specific to astrocytes and obtained from Lab Vision Corporation, Medico Co., Egypt (Cat. \#MS-280-B0). The slides were washed with phosphate buffer then incubated with the secondary anti-mouse antibodies universal kits obtained from Zymed Corporation. Incubation with substrate chromogen 3,3'-diaminobenzidine (DAB) for 5-10 min was done, which resulted in brown-coloured precipitate at the antigen sites and Mayer's haematoxylin was used as a counter stain. Positive control (brown discoloration of the glial cells mainly astrocytes denoting increase gliosis) was IMR5 cells in brain, and for negative controls, incubation was carried out with the omission of the primary antiserum [3].

\section{Electron microscopic examination}

Specimens from the cerebella were cut into small slices, fixed in $4 \%$ glutaraldehyde then washed in phosphate buffer and post-fixed in 1\% osmium tetraoxide. Fixation was followed by dehydration and embedding in epoxy resins. Semithin sections $(1 \mu \mathrm{m})$ were stained with toludine blue. Ultrathin sections (50-60 nm) were stained with uranyl acetate and lead citrate [8]. These sections were examined and photographed using a Joel, $100 \mathrm{CX}$ II transmission electron microscope.

\section{Histomorphometric measurements}

The following parameters were measured in different fields with fixed field area $4 \times 10^{4} \mu \mathrm{m}^{2}$ :

- thickness of the molecular and granular cortical layers of the cerebellum (×100 magnification);

- Purkinje cells density counted in the high power field $(\times 400)$;

- the area per cent of GFAP immune reaction in the cerebellar cortex in the high power field $(\times 400)$.

The measurements were taken by an independent observer, who was unaware of the experimental design. They were obtained in ten non-overlapping fields per specimen at a magnification of 400 by using Leica LAS, V3.8 image analyser computer system (Switzerland).

\section{Statistical analysis}

The data obtained from all groups were expressed as mean and standard deviation ( \pm SD) and subjected to statistical analysis using SPSS 22 software. Oneway analysis of variance (ANOVA) for comparison between the different groups was done. Comparison of significance between the control and various groups was made. P-values $\leq 0.05$ were considered significant and $p$-values $\leq 0.001$ were considered highly significant.

\section{RESULTS}

\section{Light microscopic examination}

Histological examination, with H\&E stain, of the specimens of the offspring of the control group aged 2 and 12 weeks (groups IA and IB), presented the normal architecture of the cerebellar cortex. The specimens showed the molecular layer which appeared as a clear zone containing few basket cells. The Purkinje cell layer consisted of one row of flask-shaped cells with large, rounded and vesicular nuclei in pale cytoplasm. The internal granular layer contained small, deeply stained granular cells. The external granular layer was found in specimens of the offspring at the age of 2 weeks consisting of small closely packed cells with deeply stained rounded nuclei (Fig. 1A, B). The specimens of the rats treated with VPA (groups IIA and IIB) showed degenerative changes of the cerebellar cortex presented with deeply stained pyknotic cells in the external granular layer. The molecular layer contained deeply stained pyknotic scattered basket cells and vacuolations. The Purkinje cells showed marked depletion, and appeared disfigured, shrunken, and surrounded with vacuolated spaces. The in- 

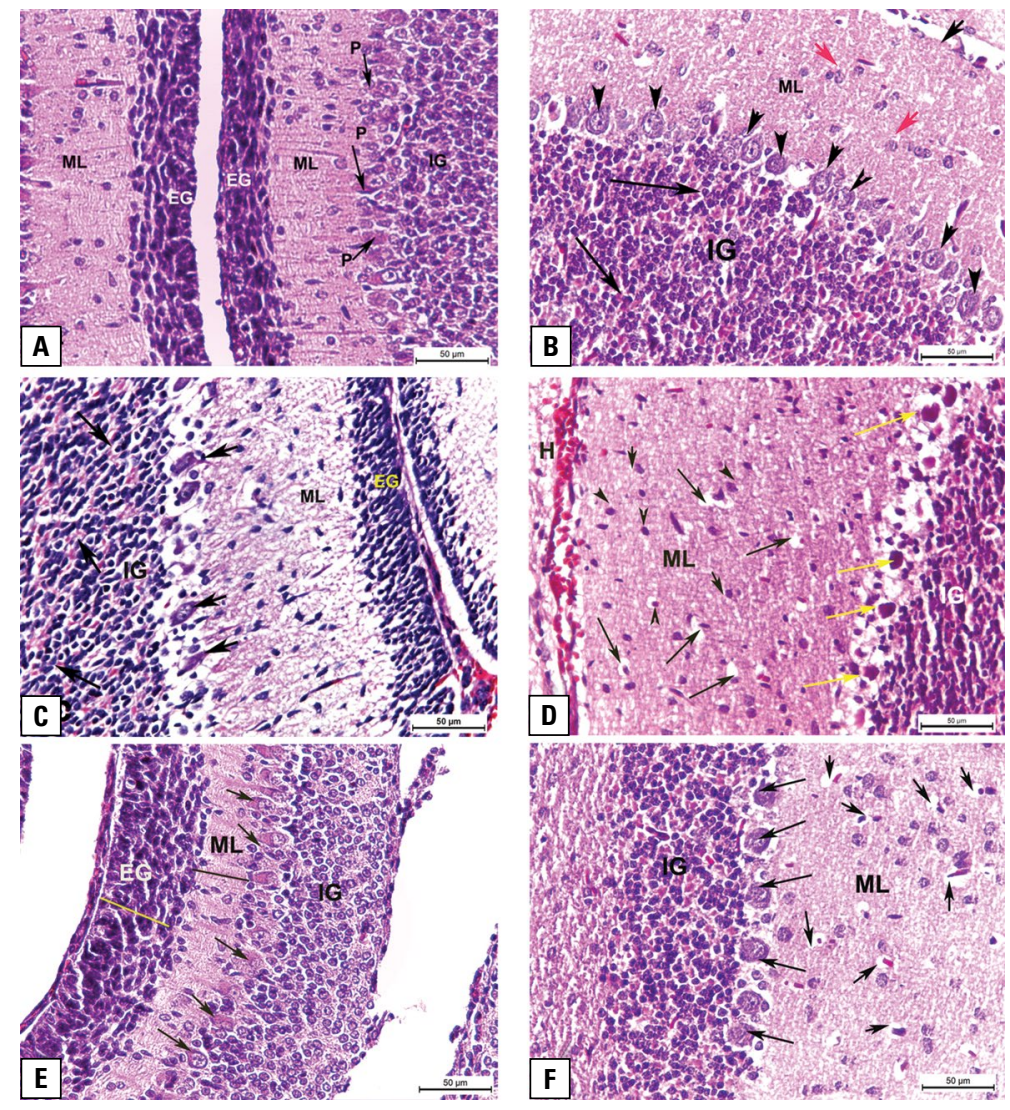

Figure 1. The cerebellar cortex: A. Group IA; B. Group IB. The molecular layer (ML) appears as a clear zone containing few basket cells (red arrows). The Purkinje cell layer (P) consists of one row of flask-shaped cells with large, rounded and vesicular nuclei in pale cytoplasm (black arrow heads). The internal granular layer (IG) contains small, deeply stained granular cells (long black arrows). Note the covering pia mater (short black arrow) and the external granular layer (EG), consisting of small closely packed cells with deeply stained rounded nuclei, in group IA. C. Group IIA; D. Group IIB. Deeply stained pyknotic cells in the external granular layer (EG). The molecular layer (ML) contains deeply stained pyknotic scattered basket cells and vacuolations. The Purkinje cells show marked depletion (short arrows), and appear disfigured, shrunken and surrounded with vacuolated spaces (yellow arrows). The internal granular layer (IG) is densely packed with small pyknotic cells (long arrows) with congested intercellular spaces. Note the haemorrhage $(\mathrm{H})$ between the cerebellar folia. E. Group IIIA; F. Group IIIB. Improvement of the cerebellar architecture. The molecular layer (ML) contains scattered basket cells with areas of vacuolation (short arrows). The Purkinje cells (long arrows) appear normal with oval shaped cells, vesicular nuclei and granular cytoplasm. The internal granular layer (IG) contains normal granular cells. The external granular layer (EG) is formed of many layers of darkly stained small granular cells in group IIIA (H\&E $\times 400)$. ternal granular layer was densely packed with small pyknotic cells intervened with congested intercellular spaces. Marked haemorrhage was seen between the cerebellar folia (Fig. 1C, D). The specimens of the experimental group treated with VPA and folic acid (groups IIIA and IIIB) showed improvement of the cerebellar architecture. The molecular layer contained scattered basket cells with minimal areas of vacuolation. The Purkinje cells appeared normal with oval shaped cells, vesicular nuclei and granular cytoplasm. The internal granular layer contained normal granular cells. The external granular layer in the 2 -week-old rats was formed of many layers of darkly stained small granular cells (Fig. 1E, F).

\section{Immunohistochemistry of GFAP}

Weak immune-expression of GFAP appeared in all layers of the cerebellar cortex in the form of brown areas in the control groups (IA and IB) (Fig. 2A, B). Strong positive immune-expression of GFAP; denoting marked gliosis and proliferation of astrocytes, in the cerebellar cortex of the groups treated with VPA (groups IIA and IIB) (Fig. 2C, D). Mild positive immuneexpression of GFAP in the different layers of the cer- ebellar cortex was found in the rats treated with VPA and folic acid (groups IIIA and IIIB) (Fig. 2E, F).

\section{Electron microscopic examination}

Specimens taken from the control group at the second and twelfth weeks (groups IA and IB) showed intact Purkinje cells, with well-defined cell membrane. Normal nuclei with regular intact nuclear envelope, finely dispersed chromatin and prominent nucleoli were found. The cytoplasm showed large number of mitochondria. Large number of myelinated and unmyelinated axons were found. Granule cells appeared with normal euchromatic rounded nuclei (Fig. 3A, B). The cerebellar cortex of the rats treated with VPA at the second week (group IIA) showed marked degeneration in the form of shrunken Purkinje cells, with irregular cell membrane. The nuclei appeared shrunken with irregular nuclear envelope, small nucleoli and rarefied chromatin. The cytoplasm showed dilated rough endoplasmic reticulum and many cytoplasmic vacuolations. Degenerated mitochondria and axons were found completely vacuolated (Fig. 3C). A large number of degenerated swollen vacuolated axons, devoid of neurofilaments and other 

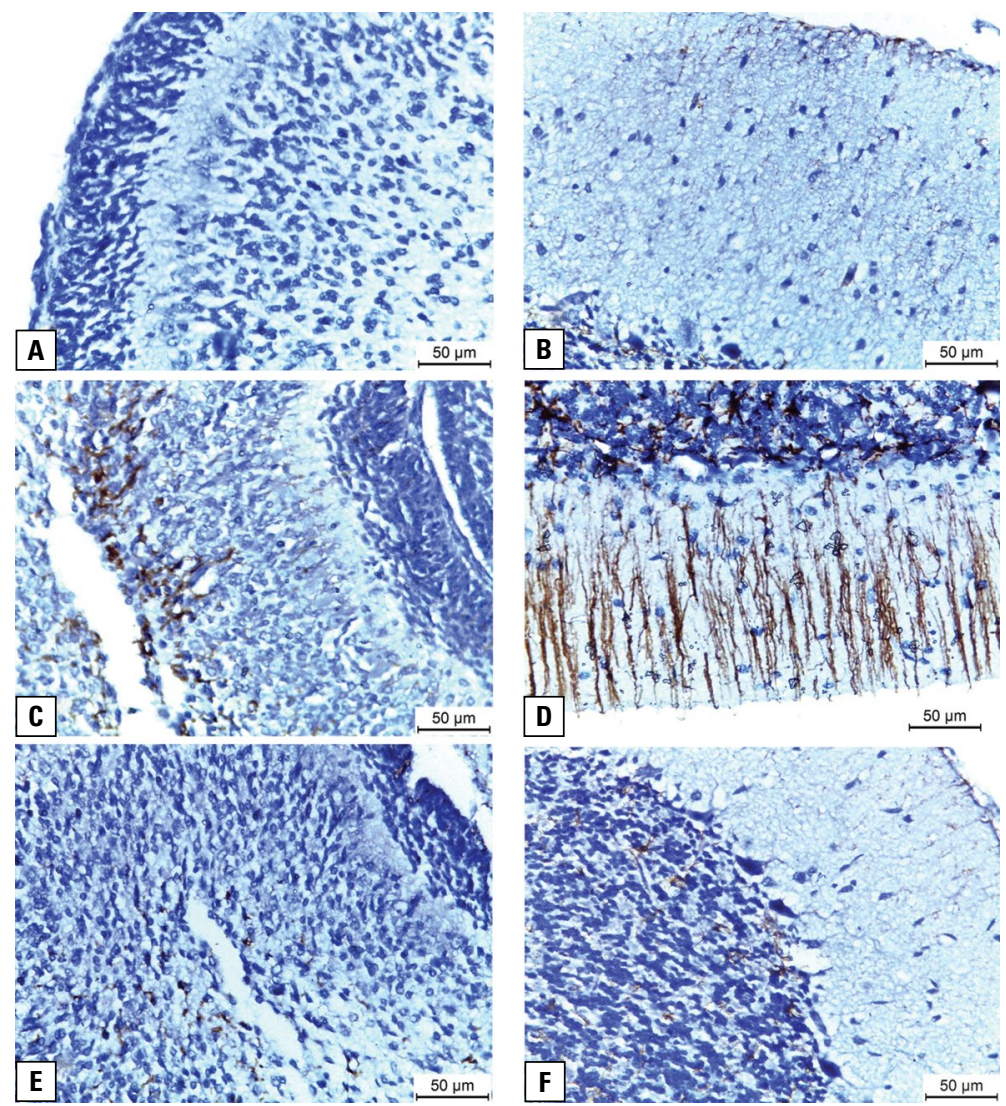

D

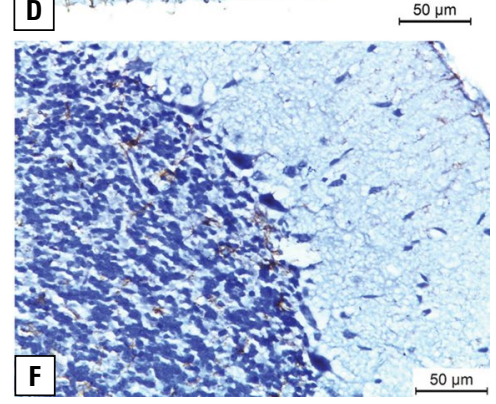

Figure 2. The cerebellar cortex. A. Group IA; B. Group IB. Weak immune expression of glial fibrillary acidic protein (GFAP) in all layers of the cerebellar cortex (brown areas). C. Group IIA; D. Group IIB. Strong positive immune expression of GFAP in the cerebellar cortex (brown areas). E. Group IIIA; F. Group IIIB. Mild positive immune expression of GFAP in the different layers of the cerebellar cortex (brown areas) (GFAP $\times 400$ ).
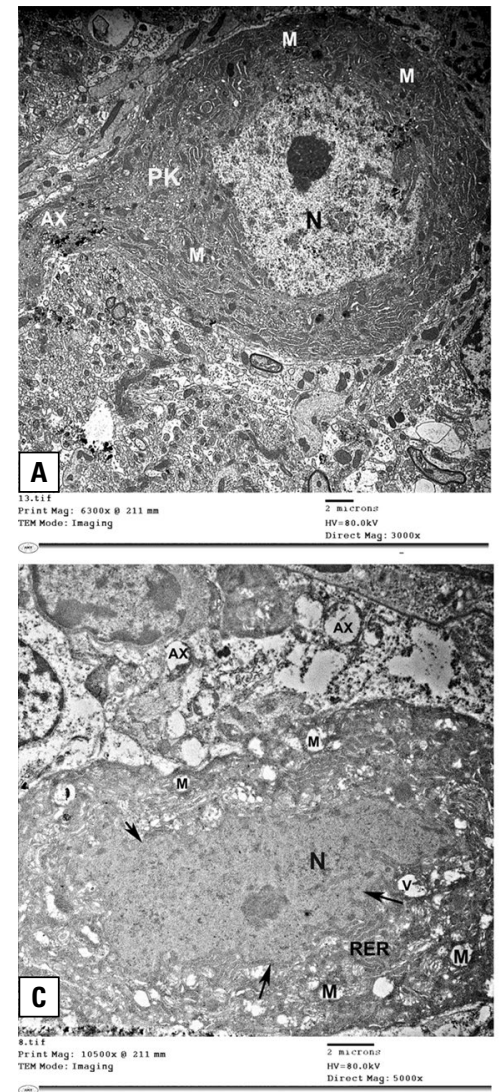
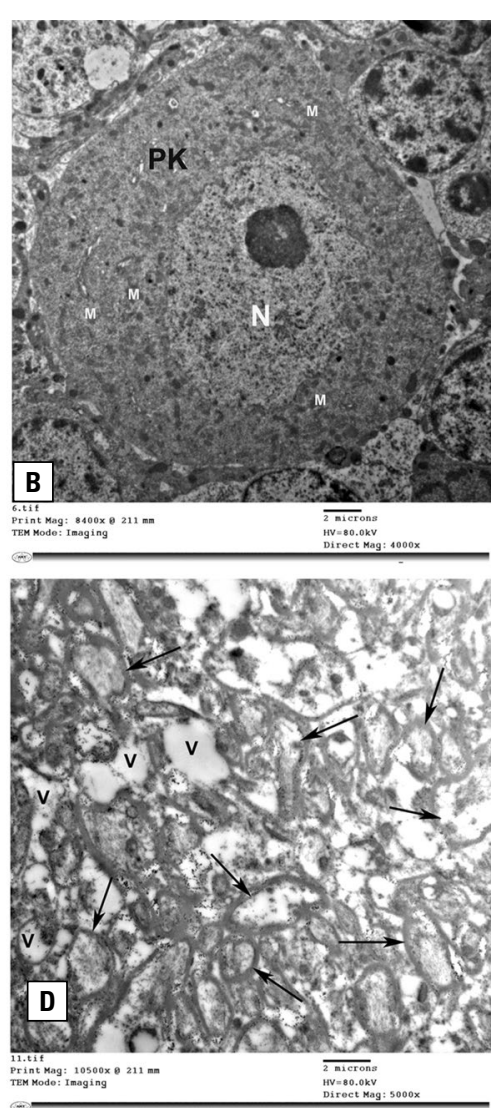

Figure 3. Electron micrographs of the cerebellar cortex. A. Group IA; B. Group IB. Intact Purkinje cell (PK). The nucleus (N) is apparently normal. The cytoplasm shows large number of mitochondria (M). Axon hillock (AX) of the cell is apparently normal. C. Group IIA. Shrunken nucleus (N) of Purkinje cell with irregular nuclear envelope (arrows). Dilated rough endoplasmic reticulum (RER) and many cytoplasmic vacuolations (V) were seen. There are many degenerated mitochondria (M). Degenerated and vacuolated axons (AX) are seen. D. Group IIA. Swollen degenerated axons (arrows). Many vacuolated axons are seen (V) (A. TEM $\times 3000$; B. $\times 4000 ;$ C. D. $\times 5000$ ) 

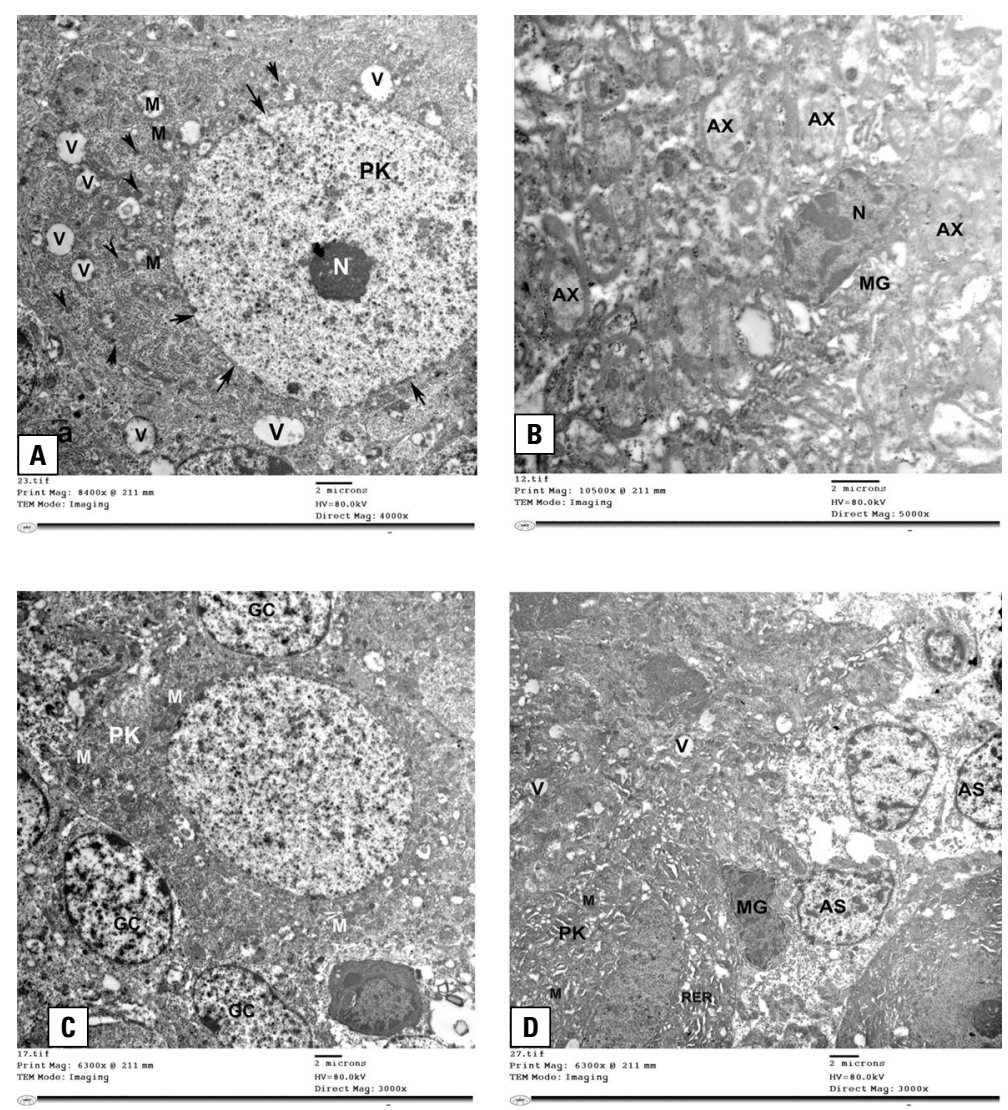

Figure 4. Electron micrographs of the cerebellar cortex. A. Group IIB. A degenerated Purkinje cell (PK) with an irregular cell membrane (arrows) and degenerated nucleus (N). Swollen empty mitochondria (M), vacuoles (V) and lysosomes (arrow heads) were seen. B. Group IIB. Large number of degenerated axons (AX). Microglial cell (MG) with an irregular nucleus is noticed. C. Group IIIA. An apparently normal Purkinje cell (PK) with normal mitochondria (M). There are many intact granular cells (GC). D. Group IIIA. Part of Purkinje cell (PK) with large number of mitochondria (M) and rough endoplasmic reticulum (RER). Adjacent to it there are many astrocytes (AS) and microglia cell (MG). Some vacuolated axons are seen (V)

$(A, D . T E M \times 4000 ;$ B. $\times 5000 ;$ C. $\times 3000)$ organelles were detected surrounding the Purkinje cells (Fig. 3D). The specimens of the same group at the twelfth week (group IIB) showed degenerated Purkinje cells with irregular cell membrane. The nuclei appeared swollen with shrunken nucleoli. The cytoplasm contained many swollen empty mitochondria and showed cytoplasmic vacuoles and many lysosomes. Large number of degenerated axons, some of them are completely devoid of neurofilaments and organelles, and microglial cells with irregular nuclei and cytoplasmic fat vacuoles were found in the specimens (Fig. 4A, B). Normal Purkinje cells appeared in the rats of the VPA and folic acid treated group at the second week (group IIIA). Their nuclei appeared vesicular with regular nuclear envelope and prominent nucleoli. The cytoplasm was found nearly normal containing many mitochondria and rough endoplasmic reticula. There were many granular cells with apparently intact cytoplasm and nuclei. Microglial cells were noticed with their characteristic nuclei and dense cytoplasm. Adjacent to Purkinje cells, many astrocytes were detected with rarefied cytoplasm and indistinct cell boundaries and some vacuolated axons were seen (Fig. 4C, D). Specimens of the rats of the same group at the twelfth week (group IIIB) showed apparently normal Purkinje cells with euchromatic nuclei, regular nuclear envelope, and finely dispersed chromatin. The cytoplasm appeared granular and rich in elongated mitochondria. Their axon hillock contained many mitochondria. Normal myelinated axons which retained their myelin sheath, their characteristic neurofilaments and mitochondria were detected (Fig. 5A, B).

\section{Histomorphometric studies}

High statistically significant reduction was detected in the density of Purkinje cells in group II at the second and twelfth weeks in comparison with the other groups. On the other hand, increase of the mean values of Purkinje cell density in group IIIA and IIIB was reported (Table 1).

Concerning the thickness of the cortical layers of the cerebellum; the external granular, the molecular and the internal granular layers, marked significant reduction was found in groups (groups IIA and IIB) compared with the other groups. Improvement of their thickness was detected in groups IIIA and IIIB (Table 2). 

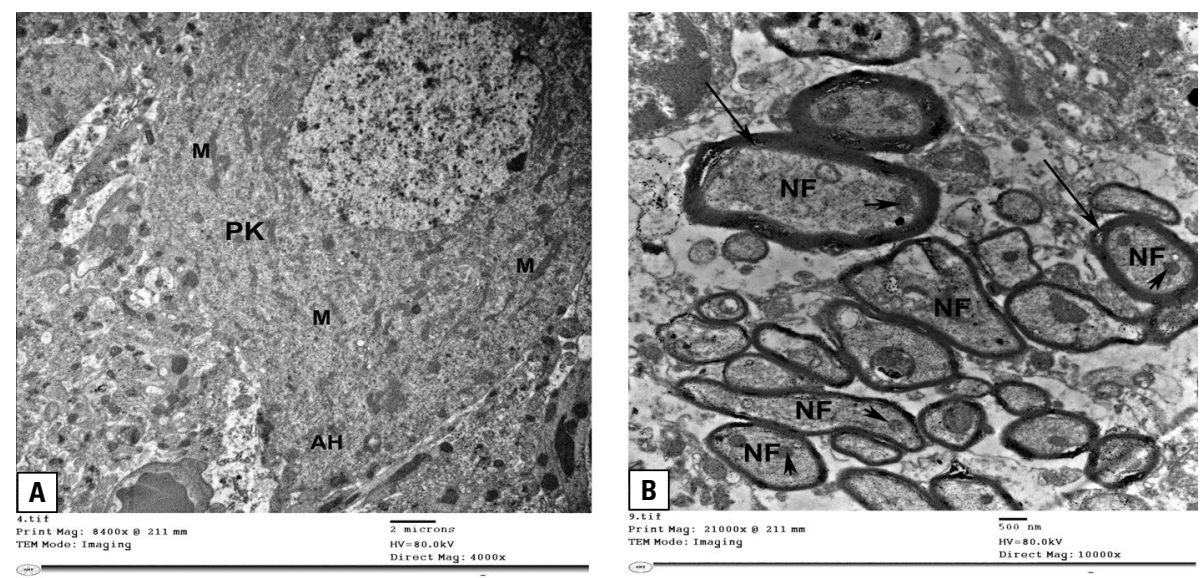

Figure 5. Electron micrographs of the cerebellar cortex. A. Group IIIB. Apparently normal Purkinje cell (PK) with elongated mitochondria (M). The axon hillock (AH) contains many mitochondria. B. Group IIIB. Apparently normal myelinated axons (long arrows) which retain their myelin sheath, their characteristic neurofilaments (NF) and rich in mitochondria (arrow heads) (A. TEM $\times 4000 ; B . \times 10000$ ).

Table 1. Mean \pm standard deviation of the neuronal density of the Purkinje cells in the cerebellar cortex in the different studied groups

\begin{tabular}{|c|c|c|c|c|c|c|}
\hline & \multicolumn{2}{|c|}{ Group I } & \multicolumn{2}{|c|}{ Group II } & \multicolumn{2}{|c|}{ Group III } \\
\hline & A & B & A & B & A & B \\
\hline Purkinje cell density & $45.15 \pm 12.8$ & $56.41 \pm 26.4$ & $24.32 \pm 23.3^{*}$ & $18.25 \pm 48.1^{*}$ & $38.46 \pm 63.2$ & $34.25 \pm 36.7$ \\
\hline
\end{tabular}

Table 2. Mean \pm standard deviation of the thickness of the different layers of the cerebellar cortex in the different experimental groups

\begin{tabular}{|c|c|c|c|c|c|c|}
\hline & \multicolumn{2}{|c|}{ Group I } & \multicolumn{2}{|c|}{ Group II } & \multicolumn{2}{|c|}{ Group III } \\
\hline & $A$ & B & $A$ & B & $A$ & B \\
\hline EGL & $216.58 \pm 21.4$ & & $164.12 \pm 63.8^{*}$ & & $186.5 \pm 36.5$ & \\
\hline $\mathrm{ML}$ & $450.81 \pm 21.2$ & $842.48 \pm 24.1$ & $314.81 \pm 13.14^{*}$ & $512.4 \pm 25.6^{*}$ & $412.81 \pm 25.6$ & $612.8 \pm 22.4$ \\
\hline IGL & $505.62 \pm 22.3$ & $972.41 \pm 21.26$ & $386.62 \pm 21.6^{*}$ & $712.8 \pm 54.61^{*}$ & $480.62 \pm 24.8$ & $784.4 \pm 51.61$ \\
\hline
\end{tabular}

*Highly significant; EGL — external granular layer; $\mathrm{ML}$ - molecular layer; IGL — internal granular layer

Table 3. Mean \pm standard deviation of the area percent of GFAP in the cerebellar cortex in the different experimental groups

\begin{tabular}{|c|c|c|c|c|c|c|}
\hline & \multicolumn{2}{|c|}{ Group I } & \multicolumn{2}{|c|}{ Group II } & \multicolumn{2}{|c|}{ Group III } \\
\hline & A & B & A & B & A & B \\
\hline GFAP & $0.15 \% \pm 13.2$ & $0.66 \% \pm 16.2$ & $4.5 \% \pm 23.1^{* *}$ & $8.25 \% \pm 41.8^{* *}$ & $2.52 \% \pm 21.2^{*}$ & $4.12 \% \pm 18.3^{*}$ \\
\hline
\end{tabular}

${ }^{*}$ Significant; **Highly significant; GFAP — glial fibrillary acidic protein

The mean area per cent of GFAP immune expression in the cerebellar cortex of the offspring of group IIA and IIB was increased with high significance compared with the other groups. Meanwhile, significant increase in the area per cent of GFAP was detected in groups IIIA and IIIB compared with the control groups (Table 3).

\section{DISCUSSION}

The present study confirmed the toxicity of VPA on the postnatal morphology and function of the cerebellar cortex of the offspring after prenatal exposure. VPA produced degenerative changes in all cerebellar layers mostly manifested on Purkinje cells. These results are consistent with many studies that 
detected the toxic effects of VPA on neuronal development $[10,21]$. Significant reduction of Purkinje cell density with absence of their processes found in the current work could be attributed to cytoskeletal depletion leading to cytoplasmic vacuolation and empty pericellular spaces. These findings are in agreement with a recent research which detected Purkinje cell atrophy proving that repeated VPA exposure disrupt the structure and function of the cerebellum [17]. In addition, axon degeneration, found in the present study was explained by damage of the vital DNA, lipids and protein macromolecules of the cells [22]. Another study claimed that the disarrangement of Purkinje cell layer, after VPA administration between the tenth and twelfth days of pregnancy, could be due to delayed migration of the cells leading to disturbance of their normal linear organisation [20]. However, the mechanism of this neurotoxic effect is still unclear. On the other hand, Kazlauskas et al. [14] found that prenatal exposure of VPA did not affect postnatal development of Purkinje cells.

Concerning the other layers of the cerebellar cortex in the present study, the molecular layer of the offspring born to VPA treated mothers featured prominent spongiosis in the form of multiple vacuolated areas and pyknotic nuclei of basket cells, while the granular layer showed pericellular unstained haloes and haemorrhage. Similar observation was mentioned by other studies who declared that VPA exacerbated the damage of granular cells with amalgamation and loss of most of the cortical architecture [11, 22].

The mechanism of neuronal degeneration could be explained by intercellular biochemical disorders such as inhibition of oxidative phosphorylation in Purkinje cell mitochondria, impairment secretory and detoxication processes, abnormal protein production or disrupted morphological cell integrity [23]. Moreover, VPA cerebellar toxicity was associated by marked elevation in the foetal oxidative stress and increase free radicals $[1,4]$. From these points of view, the present study examined the protective effect of folic acid against VPA toxicity. Prenatal folic acid deficiency produced gene expression disorders with increase foetal oxidative stress inducing impairment of protein synthesis [27]. The findings of the current work confirmed the neuroprotective effects of folic acid manifested by normal Purkinje cells, resembling those of the control groups that could be due to its antioxidant role. In addition, folic acid played an im- portant role in elimination of reactive oxygen species by prevention of lipid peroxidation [12].

Other important findings of the current work, were manifested by the proliferation of Bergmann's astrocytes, oligodendrocytes and microglial cells in the cerebellar cortex after VPA prenatal exposure. Astrocyte activation demonstrated by statistically strong positive GFAP immune reaction could be a compensatory mechanism after VPA neurodegeneration. These neuroglial cells were transformed into potentially cytotoxic cells mediated by the release of toxic reactive oxygen and nitrogen species in response to neurodegeneration [26]. Concomitant folic acid treatment with VPA in the current work induced marked improvement in the GFAP immunohistochemical reaction proving the protective effect of folic acid.

Statistically significant reduction in the thickness of all cortical layers of VPA prenatal treated offspring was in agreement with previous studies which explained the cause of these changes. VPA disrupted the cyclin-dependent kinase system which controls cellular apoptosis, division, differentiation and function $[2,5]$. Therefore, the present study examined the role of folic acid as a co-factor in the control of gene expression and protein synthesis essential for foetal cell differentiation and development protecting the neuronal cells from VPA teratogenicity. Moreover, it was proved that folic acid inhibited neuronal apoptosis acting as a coenzyme in single carbon transfers essential for the amino acid and nucleic acid metabolism [7].

\section{CONCLUSIONS}

The present study demonstrated the protective role of folic acid against the neurotoxicity of prenatal exposure of VPA affecting the cerebellar cortex. It is recommended to give folic acid supplements to the pregnant mothers treated with VPA to guard against such toxicity.

\section{REFERENCES}

1. Banji D, Banji OJF, Abbagoni S, et al. Amelioration of behavioral aberrations and oxidative markers by green tea extract in valproate induced autism in animals. Brain Res. 2011; 1410: 141-151, doi: 10.1016/j.brainres.2011.06.063, indexed in Pubmed: 21820650.

2. Barrett $C P$, Noble MEM. Molecular motions of human cyclin-dependent kinase 2. J Biol Chem. 2005; 280(14): 13993-14005, doi: 10.1074/jbc.M407371200, indexed in Pubmed: 15695825.

3. Cattoretti G, Pileri S, Parravicini $C$, et al. Antigen unmasking on formalin-fixed, paraffin-embedded tissue sections. J Pathol. 1993; 171(2): 83-98, doi: 10.1002/ path.1711710205, indexed in Pubmed: 7506771. 
4. Danielsson BR, Danielsson C, Nilsson MF. Embryonic cardiac arrhythmia and generation of reactive oxygen species: common teratogenic mechanism for IKr blocking drugs. Reprod Toxicol. 2007; 24(1): 42-56, doi: 10.1016/j. reprotox.2007.04.005, indexed in Pubmed: 17570632.

5. De Zeeuw $\mathrm{Cl}$, Hoogland TM. Reappraisal of Bergmann glial cells as modulators of cerebellar circuit function. Front Cell Neurosci. 2015; 9: 246, doi: 10.3389/fncel.2015.00246, indexed in Pubmed: 26190972.

6. Duncan J, Sander J, Sisodiya S, et al. Adult epilepsy. Lancet. 2006; 367(9516): 1087-1100, doi: 10.1016/s01406736(06)68477-8.

7. Eichholzer M, Tönz O, Zimmermann R. Folic acid: a publichealth challenge. Lancet. 2006; 367(9519): 1352-1361, doi: 10.1016/S0140-6736(06)68582-6, indexed in Pubmed: 16631914.

8. El Sa, Mohamed IA. Histological study on the protective effect of Dantrolene on cerebellar toxicity induced experimentally by methotrexate in adult male albino rats. Egy J Med Sci. 2013; 34(2): 563-583.

9. Giavini E, Menegola E. Gene-teratogen interactions in chemically induced congenital malformations. Biol Neonate. 2004; 85(2): 73-81, doi: 10.1159/000074962, indexed in Pubmed: 14631152.

10. Ingram JL, Peckham SM, Tisdale B, et al. Prenatal exposure of rats to valproic acid reproduces the cerebellar anomalies associated with autism. Neurotoxicol Teratol. 2000; 22(3): 319-324, indexed in Pubmed: 10840175.

11. Jin N, Kovács AD, Sui Z, et al. Opposite effects of lithium and valproic acid on trophic factor deprivation-induced glycogen synthase kinase-3 activation, c-Jun expression and neuronal cell death. Neuropharmacology. 2005; 48(4): 576-583, doi: 10.1016/j.neuropharm.2004.11.010, indexed in Pubmed: 15755485.

12. Joshi R, Adhikari S, Patro BS, et al. Free radical scavenging behavior of folic acid: evidence for possible antioxidant activity. Free Radic Biol Med. 2001; 30(12): 1390-1399, indexed in Pubmed: 11390184.

13. Kalhan SC, Marczewski SE. Methionine, homocysteine, one carbon metabolism and fetal growth. Rev Endocr Metab Disord. 2012; 13(2): 109-119, doi: 10.1007/s11154-0129215-7, indexed in Pubmed: 22418620.

14. Kazlauskas N, Campolongo M, Lucchina L, et al. Postnatal behavioral and inflammatory alterations in female pups prenatally exposed to valproic acid. Psychoneuroendocrinology. 2016; 72: 11-21, doi: 10.1016/j.psyneuen.2016.06.001, indexed in Pubmed: 27337090.

15. Klein AM. Epilepsy cases in pregnant and postpartum women: a practical approach. Semin Neurol. 2011; 31(4): 392-396, doi: 10.1055/s-0031-1293538, indexed in Pubmed: 22113511.

16. Lucchina L, Depino AM. Altered peripheral and central inflammatory responses in a mouse model of autism.
Autism Res. 2014; 7(2): 273-289, doi: 10.1002/aur.1338, indexed in Pubmed: 24124122.

17. Main SL, Kulesza RJ. Repeated prenatal exposure to valproic acid results in cerebellar hypoplasia and ataxia. Neuroscience. 2017; 340: 34-47, doi: 10.1016/j.neuroscience.2016.10.052, indexed in Pubmed: 27984183.

18. Martindale W. The extra pharmacopoeia. 29th edition. Pharmaceutical Press, London. 1989.

19. Pippenger CE. Pharmacology of neural tube defects. Epilepsia. 2003; 44 (Suppl 3): 24-32, indexed in Pubmed: 12790883.

20. Rossi F, Borsello T. Ectopic Purkinje cells in the adult rat: olivary innervation and different capabilities of migration and development after grafting. J Comp Neurol. 1993; 337(1): 70-82, doi: 10.1002/cne.903370105, indexed in Pubmed: 8276993.

21. Sandhya T, Sowjanya J, Veeresh B. Bacopa monniera (L.) Wettst ameliorates behavioral alterations and oxidative markers in sodium valproate induced autism in rats. Neurochem Res. 2012; 37(5): 1121-1131, doi: 10.1007/s11064-012-0717-1, indexed in Pubmed: 22322665.

22. Shalaby NM, Sarhan NI. Light and electron microscopic study on the effect of valproic acid on cerebellar cortex of adult male albino rats and the possible protective effect of L-carnitine. Egy J Histol. 2008; 31: 256-265.

23. Sobaniec-Lotowska ME. Ultrastructure of Purkinje cell perikarya and their dendritic processes in the rat cerebellar cortex in experimental encephalopathy induced by chronic application of valproate. Int J Exp Pathol. 2001; 82(6): 337-348, indexed in Pubmed: 11846840.

24. Stephen LJ, Forsyth M, Kelly K, et al. Antiepileptic drug combinations--have newer agents altered clinical outcomes? Epilepsy Res. 2012; 98(2-3): 194-198, doi: 10.1016/j.eplepsyres.2011.09.008, indexed in Pubmed: 21982026.

25. Vajda F. Dose issues in antiepileptic therapy. J Clin Neurosci. 2012; 19(11): 1475-1477, doi: 10.1016/j. jocn.2012.05.003, indexed in Pubmed: 22959449.

26. Vilhardt F. Microglia: phagocyte and glia cell. Int J Biochem Cell Biol. 2005; 37(1): 17-21, doi: 10.1016/j.biocel.2004.06.010, indexed in Pubmed: 15381143.

27. Wegner C, Nau H. Alteration of embryonic folate metabolism by valproic acid during organogenesis: implications for mechanism of teratogenesis. Neurology. 1992; 42(4 Suppl 5): 17-24, indexed in Pubmed: 1574172.

28. Wilson RD, Johnson JA, Wyatt $P$, et al. Pre-conceptional vitamin/folic acid supplementation 2007: the use of folic acid in combination with a multivitamin supplement for the prevention of neural tube defects and other congenital anomalies. J Obstet Gynaecol Can. 2007; 29(12): 1003-1013, doi: 10.1016/\$1701-2163(16)32685-8, indexed in Pubmed: 18053387. 